\title{
ANTIMICROBIAL EFFECTS IN MANAGEMENT OF WASTEWATER TREATMENT PLANTS
}

\section{Manisha Gunasekera, Indrika Abeygunawardana and Ajith De Alwis \\ Department of Chemical Engineering, University of Moratuwa.}

Many wastewater treatment plants operating today in various industries have one or more biological treatment component. which could be either aerobic or anacrobic. or a combination of both. The type of biological treatment utilised will vary from one plant to another depending on the nature of the wastewater treated. Industries such as chemical process, pharmaceutical etc. have to pay more attention to their wastewater sent to the wastewater treatment plant as these wastewaters may contain substances in quantities which can cause harmful effects to the living organisms in the biological treatment system, thus action should be taken to reduce these antimicrobial substances entering the biological treatment component of the wastewater treatment plant to levels to which the biological population is more capable of handling those in the degradation process. An action to manage this type of situation will call for the need for monitoring techniques or quantities.

In this concept paper, online and offline monitoring techniques of such substances and its management concepts are illucidated. In monitoring wastewater the use of the parameter $B O D$ and the inhibition chatacteristics of the microorganism were looked at with reference 10 wastewater trom a pharmaceutical manufacturing industry. 